\title{
Shear strength of unsaturated completely decomposed granite soil under different stress state conditions
}

\author{
Wan-Huan Zhou ${ }^{\text {i) }}$ and $\mathrm{Xu} \mathrm{Xu}{ }^{\text {ii) }}$ \\ i) Assistant Professor, Department of Civil and Environmental Engineering, University of Macau, Taipa, Macau, China. \\ ii) MSc., Department of Civil and Environmental Engineering, University of Macau, Taipa, Macau, China.
}

\begin{abstract}
The shear strength of unsaturated completely decomposed granite (CDG) soil was studied by performing a series of unsaturated direct shear tests under different combinations of net normal stress and matric suction conditions. The axis-translation technique is applied to control matric suction. A series of typical soil water characteristic curves (SWCC) of CDG soil under different net normal stresses were obtained considering consolidation process by monitoring the vertical displacement throughout the tests. Experimental results show that both unsaturated shear strength and SWCC are affected by the soil stress states. Shear dilation behavior is observed significantly obvious at higher suction and lower net normal stress state, and the shear strength of unsaturated CDG soil increases with matric suction and net normal stress.
\end{abstract}

Keywords: unsaturated soil, shear strength, matric suction, net normal stress, soil-water characteristic curve, direct shear test

\section{INTRODUCTION}

The shear strength of soil is very important to analyze stability problems, such as slope stability, bearing capacity, and lateral earth pressure on retaining structures. The shear strength parameters are also required to be determined by field or laboratory tests before engineering design or safety assessment. Conventional Mohr-Coulomb theory is widely used for fully saturated soils. However, most soils in the shallow foundation are typically in unsaturated condition. The development of unsaturated soil mechanics has never been stopped and a whole system of unsaturated soil mechanics was set up about twenty years ago (Fredlund and Rahardjo 1993).

A number of studies have been conducted on the experimental determination of shear strength of unsaturated soils. For the experimental study, a very important issue is to control and measure the matric suction in the soil throughout testing process. The most commonly used technique is axis-translation technique (Hilf 1956), and its basic principle is to translate the origin of reference for the pore-water pressure measurement from standard atmospheric conditions $\left(\mathrm{u}_{\mathrm{a}}=0, \mathrm{u}_{\mathrm{w}}<0\right)$ to the desired final air pressure value $\left(u_{a}>0, u_{w} \geq 0\right)$. The independent control of the pore-air and pore-water pressure requires the use of high air-entry ceramic disk. When the disk is fully saturated, it acts as a membrane between air phase and water phase, which allows the slow passage of water but does not permit the flow of free air as long as the difference between the air and water pressure does not exceed the air-entry value of the disk. In this way, numerous researchers applied axis-translation technique to control and measure the matric suction for unsaturated direct shear test, ring shear test, and triaxial shear test (Gan and Fredlund 1994; Lee et al. 2005; Zhan and Ng 2006; Hossain and Yin 2010; Hoyos et al. 2010; Schnellmann et al. 2013).

The main objective of this study is to investigate the real shear strength behaviour of unsaturated CDG soil under different stress state conditions by using unsaturated direct shear apparatus, which is based on the previous studies of unsaturated soils (Zhou and $\mathrm{Xu}$ 2014, Zhou et al. 2014, Zhou and Zhao 2014). A series of typical soil water characteristic curves (SWCC) of CDG under different net normal stresses were obtained considering consolidation process by monitoring the vertical displacement throughout the tests. The influences of matric suction $(\psi)$ and net normal stress (NNS) on SWCC and unsaturated shear strength were discussed and interpreted in details.

\section{SHEAR STRENGTH EQUATION OF UNSATURATED SOIL}

There are several formulations for evaluating the shear strength of unsaturated soil in terms of different state variables. Bishop (1959) proposed the original 
unsaturated shear strength equation by incorporating the unsaturated soil effective stress theory into the classical Mohr-Coulomb failure criterion. This equation is expressed as follows:

$$
\tau=c^{\prime}+\left[\left(\sigma_{n}-u_{a}\right)+\chi\left(u_{a}-u_{w}\right)\right] \tan \phi^{\prime}
$$

where $\tau=$ unsaturated shear strength; $\mathrm{c}^{\prime}=$ effective cohesion at saturation; $\phi^{\prime}=$ effective friction angle at saturation; $\mathrm{u}_{\mathrm{a}}=$ pore air pressure; $\mathrm{u}_{\mathrm{w}}=$ pore water pressure; $\sigma_{\mathrm{n}}=$ total stress; $\left(\sigma_{\mathrm{n}}-\mathrm{u}_{\mathrm{a}}\right)=$ net normal stress; $\left(\mathrm{u}_{\mathrm{a}}-\mathrm{u}_{\mathrm{w}}\right)=$ matric suction; and $\chi=$ effective stress parameter varying from 1 for a saturated condition to 0 for a completely dry condition. However, several researchers have shown the difficulties of quantifying the value of $\chi$ both theoretically and experimentally, because it depends on so many factors, such as wetting history, loading path, soil type, internal structure of the soil, specimen size and so on (Fredlund and Morgenstern 1977).

In order to avoid such limitations, Fredlund and Morgenstern (1977) proposed two independent variables, i.e., net normal stress $\left(\sigma_{\mathrm{n}}-\mathrm{u}_{\mathrm{a}}\right)$ and matric suction $\left(u_{a}-u_{w}\right)$ to describe the stress state of unsaturated soils, and Fredlund et al. (1978) formulated the following shear strength equation of unsaturated soil, which is written as follows:

$$
\tau=c^{\prime}+\left(\sigma_{n}-u_{a}\right) \tan \phi^{\prime}+\left(u_{a}-u_{w}\right) \tan \phi^{b}
$$

where $\phi^{\mathrm{b}}=$ angle of shearing resistance with respect to matric suction. When $u_{a}$ is equal to the $u_{w}$ (fully saturated condition), the first two terms actually is the classical Mohr-Coulomb failure criterion, so Eq. (2) makes a smooth extension from saturated soil to unsaturated soil. Besides, the third term introduces a parameter $\phi^{\mathrm{b}}$ related to matric suction.

\section{SOIL PROPERTIES AND TESTING PROGRAM}

\subsection{Soil properties}

A typical residual soil of Macau, Completely Decomposed Granite (CDG) soil, was used in present study. Soil specimens were taken from a slope near the University of Macau, Taipa. Basic property tests were carried out on CDG soil according to the specifications of ASTM, particle-size distribution result is shown in Fig.1. Based on the test results, CDG soil is classified as silty sand (SM), according to USCS (ASTM 1992). In summary, the basic parameter values of soil properties are shown in Table 1.

Table 1. Basic properties of CDG soil.

\begin{tabular}{cccccccc}
\hline Soil & $\mathrm{G}_{\mathrm{s}}$ & $\begin{array}{c}\mathrm{OMC} \\
(\%)\end{array}$ & $\begin{array}{c}\rho_{\mathrm{dmax}} \\
\left(\mathrm{Mg} / \mathrm{m}^{3}\right)\end{array}$ & $\begin{array}{c}\mathrm{LL} \\
(\%)\end{array}$ & $\begin{array}{c}\text { PL } \\
(\%)\end{array}$ & $\begin{array}{c}\text { PI } \\
(\%)\end{array}$ & USCS \\
\hline CDG & 2.68 & 16.5 & 1.73 & 38 & 28 & 10 & $\mathrm{SM}$ \\
\hline
\end{tabular}

\subsection{Sample preparation}

The initial moisture content of CDG powder was about $3 \%$. All the specimens were directly prepared to achieve the degree of saturation around 95\%, gravimetric water content of $23.3 \%$ and void ratio of 0.624 as the same initial condition, instead of fully saturation after compaction, in order to minimize the water volume change error.

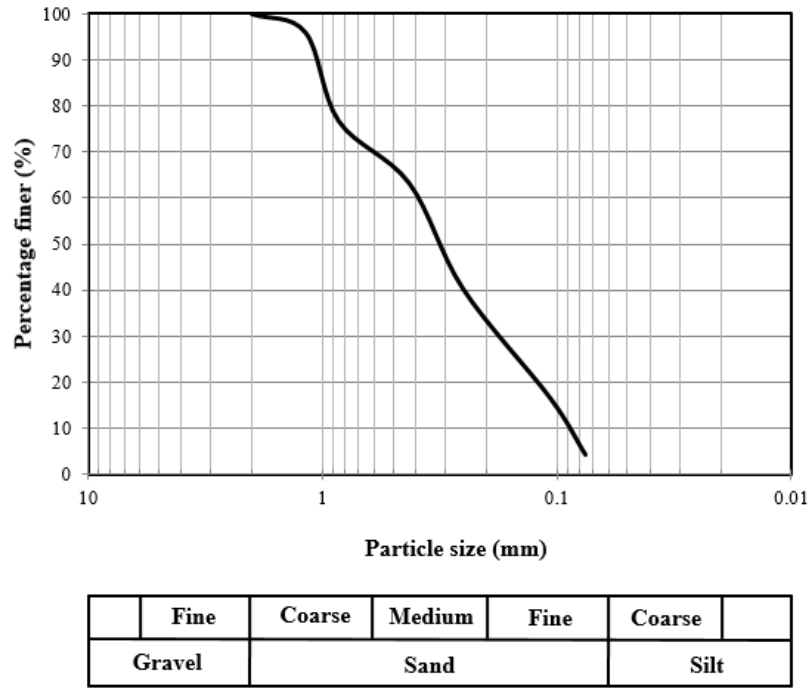

Fig. 1. Particle-size distributions of CDG soil.

A special square mold $(100 \mathrm{~mm} \times 100 \mathrm{~mm} \times 60 \mathrm{~mm})$ was manufactured with a removable base and cap for sample extruding. The soil specimen was prepared by compacting sample in the mold in four equal layers $(10 \mathrm{~mm}$ each layer). In order to produce a uniform sample with the size of $100 \mathrm{~mm} \times 100 \mathrm{~mm} \times 40 \mathrm{~mm}$, the required mass of wet soil for each layer was carefully controlled and compacted to a certain height using a ruler to measure four sides, to finally achieve a dry density of $1.65 \mathrm{Mg} / \mathrm{m}^{3}$, which was $95 \%$ of the maximum dry density of $1.73 \mathrm{Mg} / \mathrm{m}^{3}$.

\subsection{Testing procedures}

The direct shear apparatus used in this study was modified from unsaturated direct shear box and set up in the geotechnical laboratory of the University of Macau. An inner cross section of $100 \mathrm{~mm} \times 100 \mathrm{~mm}$ shear box was produced with a 5 bar high air-entry value ceramic disk (manufactured by Soilmoisture Equipment Corp.,) installed at the bottom of lower shear box to control the matric suction. Both SWCC tests and direct shear tests were performed with the application of axis-translation technique by using unsaturated direct shear apparatus under different stress state conditions.

SWCC tests were conducted under different net normal stresses $(0,25,50,100,200 \mathrm{kPa})$ respectively, and the settlement was measured by a vertical LVDT with the increasing matric suction values $(0,25,50,75$, $100,150,200,300$, up to $400 \mathrm{kPa})$. The procedures of 
this test mainly consist of three parts: First, the prepared sample in the shear box should be quickly placed into air chamber and applied first stage normal stress and air pressure, in case that soil absorbed water from the water compartment below the ceramic disk. Second, equilibrium of suction and normal stress would be achieved in about 24 hours, until no water drained out from the sample. During the equilibration process, vertical deformation and water volume were measured and recorded. Third, air pressure was increased in order to get the equilibrium under a higher suction, until the maximum suction $400 \mathrm{kPa}$ was applied to the specimen. Finally, the water content of soil sample was measured after the last equilibrium finished.

The equilibrium process of unsaturated direct shear test were generally similar to SWCC test. Each sample in the air chamber was directly applied to specific target matric suction and net normal stress. When reaching equilibrium, shearing was conducted under a drained condition. Compared to the shearing of saturated soil, the shearing rate of unsaturated soil should be very slow, to ensure the drained condition and uniform matric suction distribution in the soil. The shearing was performed under constant shearing rate of $0.01 \mathrm{~mm} / \mathrm{min}$ until the horizontal displacement reached $15 \mathrm{~mm}$. After the completion of shearing, the drainage line was closed and the air pressure in the chamber was released. The sample was quickly dismantled from the shear box for the determination of final water content.

\section{EXPERIMENTAL RESULTS AND DISCUSSIONS}

\subsection{SWCC results under different net normal stresses}

A series of typical SWCCs of CDG soil under different net normal stresses were obtained by using unsaturated direct shear apparatus. It should be noted that the SWCC in terms of volumetric water content was deduced from the settlement measurement for each sample when it achieved equilibrium at each of pressure stage considering the specimen volume change, as shown in Fig. 2.

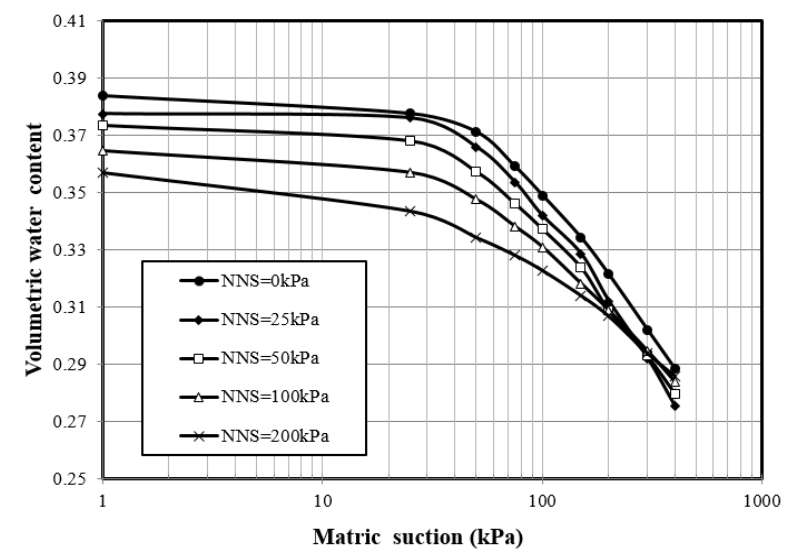

Fig. 2. SWCCs of CDG soil under different net normal stresses.
It can be seen that the higher net normal stress results in the lower initial volumetric water content. On the contrary, the increase of net normal stress leads to the increase of air-entry value of soil. This is consistent with the general tendency, as noted in the literatures, substantially due to a smaller void ratio of the soil specimen under a higher net normal stress $(\mathrm{Ng}$ and Pang 2000; Lee et al. 2005; Kim and Borden 2011). It is seen from Fig. 3, due to consolidation, void ratio for each pressure stage was decreasing. When the net normal stress was specified, settlement was observed to increase as the matric suction increases. For the same matric suction, a larger net normal stress resulted in a larger settlement. In this case, the applied matric suction and net normal stress would have an influence on the void ratio as well as the calculation of volumetric water content. It should be noted that if consolidation was not taken into account, it would be underestimate the normalized volumetric water content $\left(\Theta=\theta / \theta_{\mathrm{s}}\right)$.

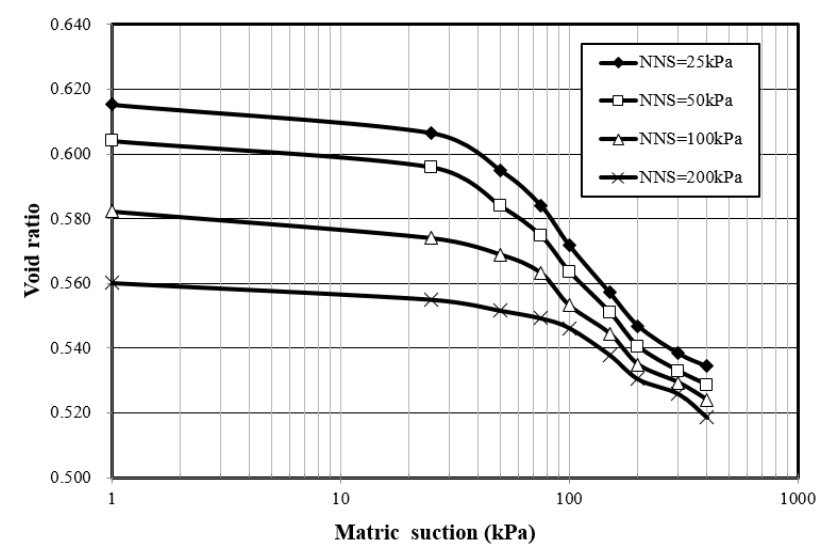

Fig. 3. Void ratio versus matric suction.

\subsection{Water volume change interpretation}

In the present experimental study, it should be noted that when the soil sample was applied target net normal stress and matric suction step by step, the volume of water drained out consisted of two parts: one caused by air and the other one caused by consolidation. Air came into the soil, took the place of water phase, so that water gradually came out until equilibrium stage reached. However, at the same time, consolidation also caused water drainage. These two components were coupled together throughout the equilibrium process. According to continuity requirement, the total volume of water drained out must be the sum of water drainage caused by air replacement and consolidation, which could be written as:

$$
\Delta V_{w}=\Delta V_{a}+\Delta V_{c}
$$

where $\Delta \mathrm{V}_{\mathrm{w}}$ is total water volume change, $\Delta \mathrm{V}_{\mathrm{a}}$ is the component of water volume change caused by air, $\Delta \mathrm{V}_{\mathrm{c}}$ is the component of water volume change caused by consolidation. 
The volume change relationship based on Eq. (3) is presented in Fig. 4. It can be found from Fig. 4, for a specified net normal stress, the volume of water drained out increases as the matric suction increases. Fig. 4(a) reveals that before $200 \mathrm{kPa}$ matric suction, more water would drain out caused by air under higher net normal stress than lower net normal stress. However, after $200 \mathrm{kPa}$ matric suction, it shows an inverse trend. Fig. 4(b) reveals higher net normal stress results in a small value of water volume change caused by consolidation, which is due to over consolidation.
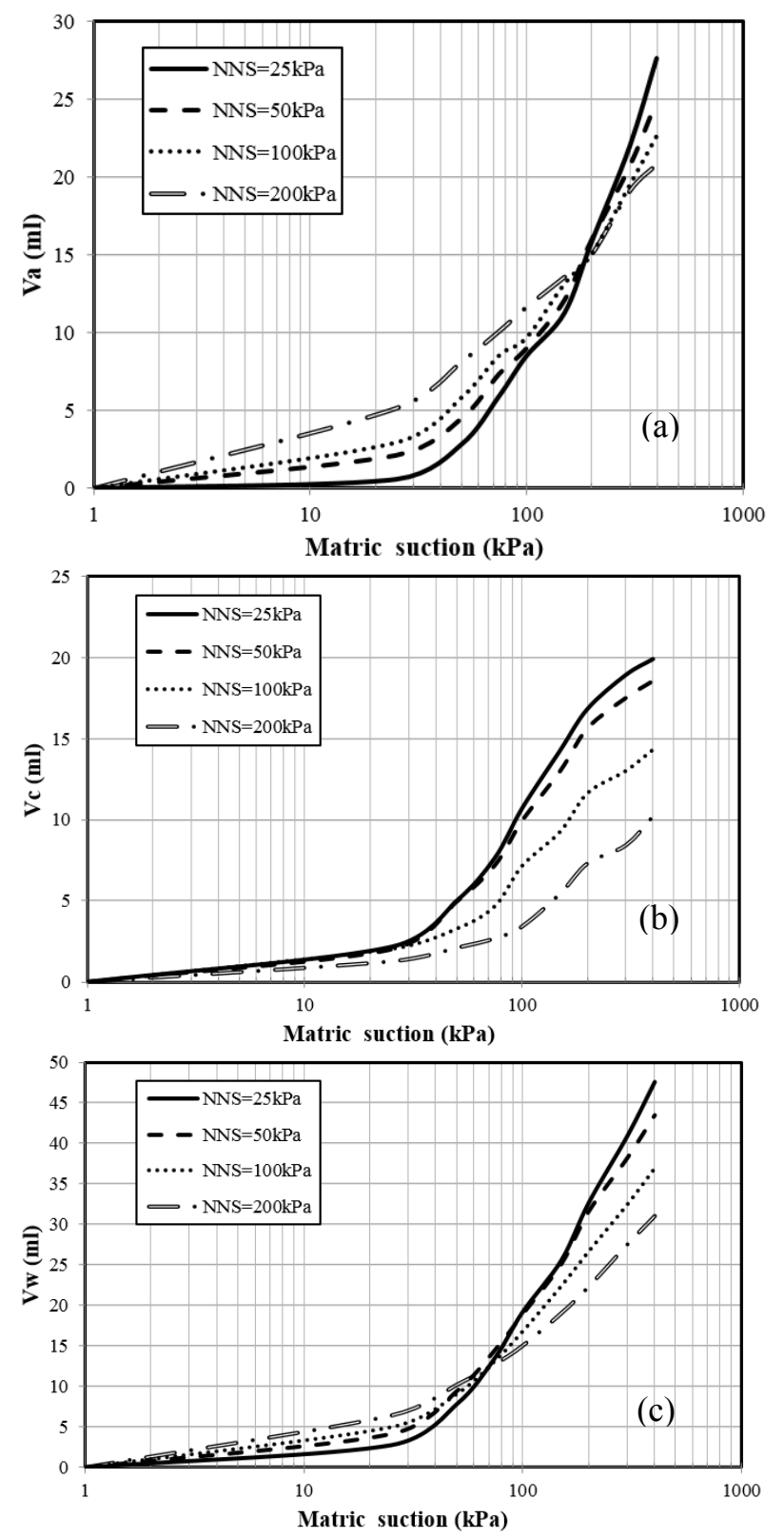

Fig. 4. Water volume change under different net normal stresses: (a) caused by air; (b) caused by consolidation; (c) total water volume change.

Fig. 4(c) has a similar trend as Fig. 4(a), indicating before $70 \mathrm{kPa}$ matric suction, more water would drain out under higher net normal stress than lower net normal stress. However, after $70 \mathrm{kPa}$ matric suction, it shows that higher net normal stress results in a smaller value of total water volume change.

\subsection{Direct shear test results}

The direct shear tests were performed under different net normal stresses (i.e., 25, 50, 100 and $200 \mathrm{kPa}$ ), and different matric suction values (i.e., 0,25 , 50,100 and $200 \mathrm{kPa}$ ) respectively to obtain the failure envelopes.

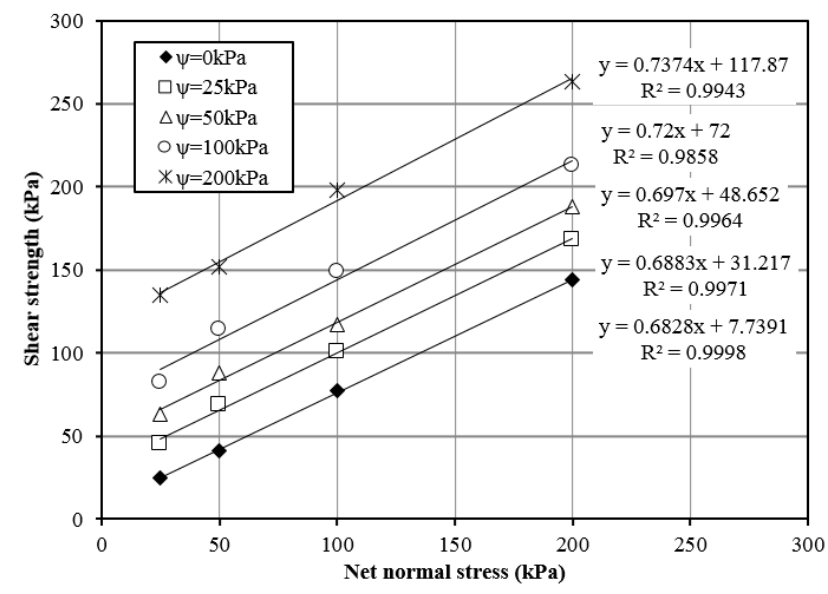

Fig. 5. Failure envelopes with respect to different matric suctions.

According to experimental results, failure envelopes of the shear strength versus net normal stress under different matric suction values are shown in Fig. 5. It is observed that the failure envelopes with respect to net normal stress reveal an approximately linear behavior for all matric suctions, and the slope of the linear relationship slightly increases as the matric suction increases, indicating the effective friction angle has a little increase with the increasing of matric suction as shown in Fig.6. So the effective friction angle can be assumed constant for most practical purposes, when suction value is not very high. Besides, it can be seen from Fig. 7 that the cohesion has a remarkable improvement as matric suction increases, proving that matric suction contributes to cohesion and shear strength significantly. Furthermore, the cohesion increment is greater in the lower matric suction range than higher suction range, indicating parameter $\phi^{\mathrm{b}}$ is not constant. The cohesion with respect to matric suction can be defined by the following equation, according to Mohr-Coulomb failure criterion and Eq. (2):

$$
c=c^{\prime}+\left(u_{a}-u_{w}\right) \tan \phi^{b}
$$

Fig. 8 reveals the variations of $\phi^{\mathrm{b}}$ with matric suction based on Eq. (4), which gives a general trend that $\phi^{b}$ value decreases with matric suction, showing a non-linear relationship. The decreasing rate is faster in the lower matric suction range, compared to higher suction range. 


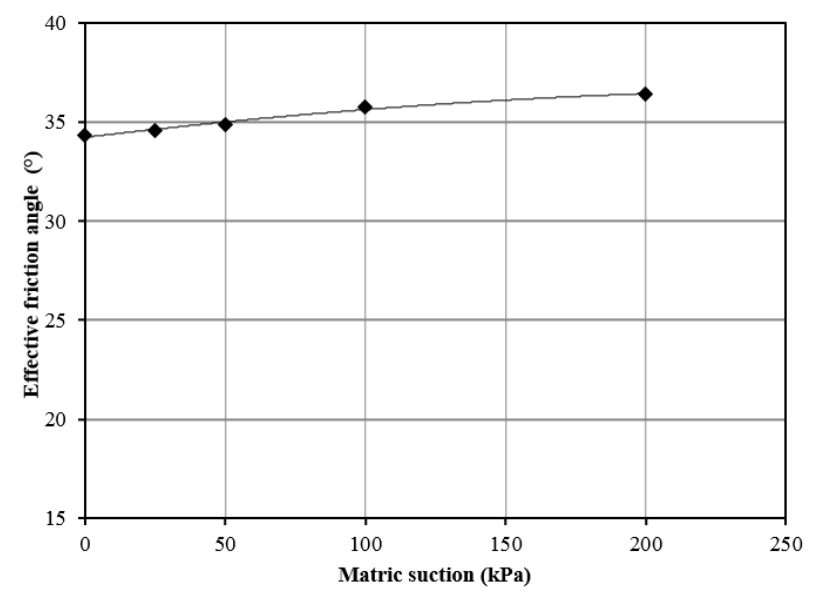

Fig. 6. Variation of effective friction angle with matric suction.

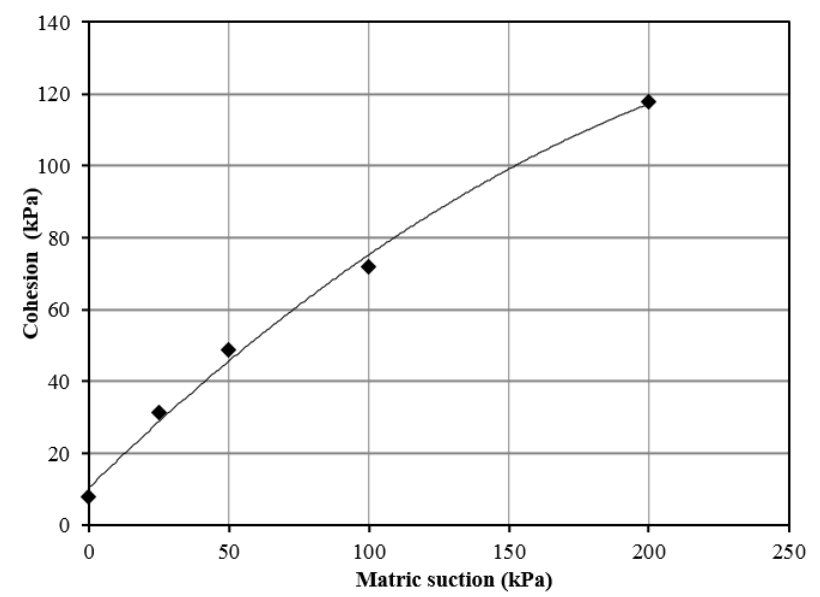

Fig. 7. Contribution of matric suction to cohesion.

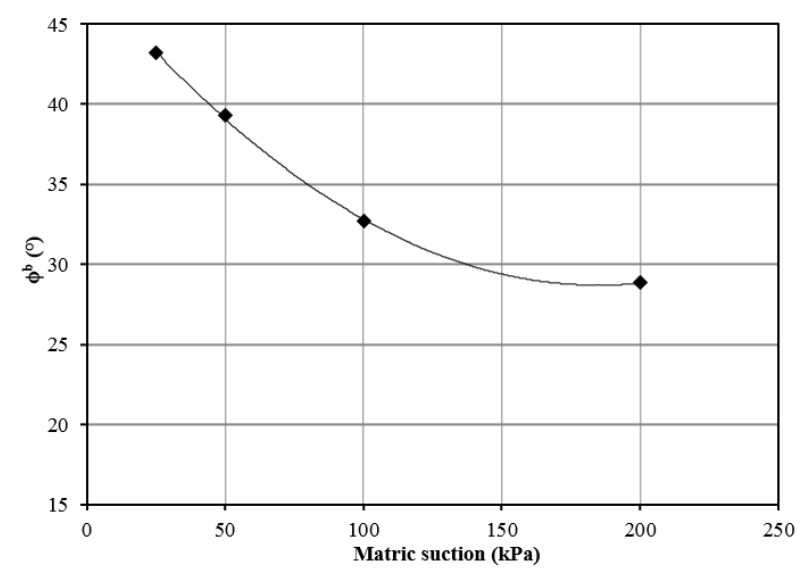

Fig. 8. Variation of $\phi^{\mathrm{b}}$ with matric suction.

Based on the experimental data, the relationship of shear strength with respect to matric suction under constant net normal stresses is non-linear, as shown in Fig. 9. The shear strength of unsaturated soil goes up with matric suction, and meanwhile the failure envelope moves up with the increasing net normal stress. Therefore, these two stress state variables finally determine the shear strength value of unsaturated soil.

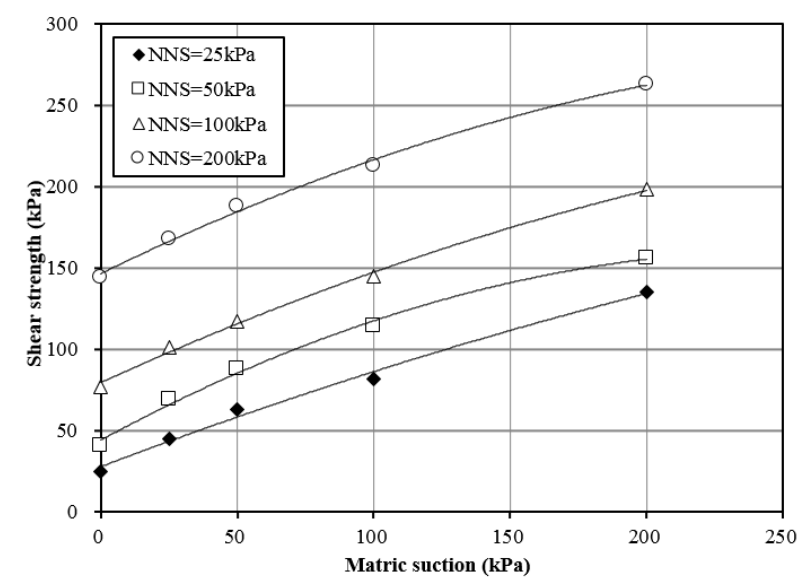

Fig. 9. Failure envelopes with respect to different net normal stresses.

\section{CONCLUSIONS}

This paper mainly presents experimental test results and their interpretation on shear strength behavior of unsaturated CDG soil. SWCC tests and direct shear tests under different stress states conditions were carried out using unsaturated direct shear apparatus. The following conclusions are drawn based on the laboratory study:

(1) The test results indicate that net normal stress and matric suction have a significant influence on the shear strength of unsaturated CDG soil.

(2) The higher matric suction and lower net normal stress show a strain softening behavior together with a remarkable shear dilation phenomena, while the lower matric suction and higher net normal stress show a strain hardening behavior together with continuous shear compression.

(3) The shear strength envelopes with respect to net normal stress show an approximately linear behavior under a constant matric suction value. However, the shear strength envelopes with respect to matric suction show a nonlinear relationship under a constant net normal stress value.

(4) From the experimental work, it can be found that net normal stress affects soil-water characteristic curve of soil. Thus, it is suggested that for the laboratory determination of SWCC, volume change under specific stress state should be taken into account throughout the test.

\section{ACKNOWLEDGEMENTS}

The authors gratefully acknowledge the financial support from the Macau Science and Technology Development Fund (FDCT/011/2013/A1 and FDCT /125/2014/A3) and the University of Macau Research Funds (MYRG2014-00175-FST, MYRG2015-00112FST and MRG025-ZWH-2015-FST). 


\section{REFERENCES}

1) ASTM. (1992). "Standard test method for classification of soils for engineering purposes." D2487-90, West Conshohocken, Pa., 326-336.

2) Bishop, A. W. (1959). "The principle of effective stress." Lecture delivered in Oslo, Norway, in 1955. Tek. Ukeblad, 106(39), 859-863.

3) Fredlund, D. G., and Morgenstern, N. R. (1977). "Stress state variables for unsaturated soils." J. Geotech. Eng. Div., 103(GT5), 447-466.

4) Fredlund, D. G., Morgenstern, N. R., and Widger, R. A. (1978). "The shear strength of unsaturated soils." Can. Geotech. J., 15(3), 313-321.

5) Fredlund, D. G., and Rahardjo, H. (1993). Soil mechanics for unsaturated soils, Wiley, New York.

6) Gan, J. K. M., and Fredlund, D. G. (1994). "Direct shear and triaxial testing of a Hong Kong soil under saturated and unsaturated condition." GEO Rep. No. 46, Geotechnical Engineering Office, Hong Kong.

7) Hilf, J. W. (1956). "An investigation of pore water pressure in compacted cohesive soils." Technical Rep. No. 654, Bureau of Reclamation, Denver.

8) Hossain, M. A., and Yin, J. H. (2010). "Behavior of a compacted completely decomposed granite soil from suction controlled direct shear tests." Journal of Geotechnical and Geoenvironmental Engineering. 136(1): 189-198.

9) Hoyos, L. R., Velosa, C. L., Puppala, A. J. (2010). “A novel suction-controlled ring shear testing apparatus for unsaturated soils." ASCE, 2010 GeoShanghai International Conference. Shanghai, China, pp. 32-39.

10) Kim, W. S., and Borden, R. H. (2011). "Influence of soil type and stress state on predicting shear strength of unsaturated soils using the soil-water characteristic curve." Can. Geotech. J., 48(12), 1886-1900.

11) Lee, I. M., Sung, S. G., and Cho, G. C. (2005). "Effect of stress state on the unsaturated shear strength of a weathered granite." Can. Geotech. J., 42, 624-631.

12) Ng, C. W. W., and Pang, Y. W. (2000). "Influence of stress state soil-water characteristics and slope stability." Journal of Geotechnical and Geoenvironmental Engineering, 126(2): 157-166.

13) Schnellmann, R, Rahardjo, H, and Schneider, H. R. (2013). "Unsaturated shear strength of a silty sand." Engineering Geology. 162: 88-96.

14) Zhan, L. T., and Ng, C. W. W. (2006). "Shear strength characteristics of an unsaturated expansive clay." Can. Geotech. J., 43, 751-763.

15) Zhou W. H. and Xu X. (2014) Unconfined compression strength of unsaturated completely decomposed granite soil with different clay mixing ratios, Geomechanics from Micro to Macro - Soga et al. (Eds), Publisher: Taylor \& Francis Group, London, ISBN 978-1-138-02707-7. Proceedings of IS-Cambridge 2014, Cambridge, UK, 1-3 September, 2014, pp. 1341-1346.

16) Zhou W. H., Zhao L. S. and Li X. B. (2014). "A simple analytical solution to one-dimensional consolidation for unsaturated soil." International Journal for Numerical and Analytical Methods in Geomechanics. Vol. 38: 794-810.

17) Zhou W. H., and Zhao L. S. (2014). "One-dimensional consolidation of unsaturated soil subjected to time-dependent loading with various initial and boundary conditions." International Journal of Geomechanics, ASCE. 14(2): 291-301. 